\title{
O Sofrimento Emocional de Filhos de Alcoolistas: Uma Compreensão Psicanalítica Winnicottiana
}

\author{
Antonio Richard Carias ${ }^{1}$ \\ Tania Mara Marques Granato ${ }^{1}$ \\ ${ }^{1}$ Pontifícia Universidade Católica de Campinas, SP, Brasil. $\quad$ 'Pontifícia Universidade Católica de Campinas, SP, Brasil.
}

Resumo: Os filhos de alcoolistas sofrem com os inúmeros dilemas provenientes da relação conturbada com o progenitor, destacando-se a violência doméstica, a desqualificação moral, a insegurança e as dificuldades financeiras. A fim de acessar os sentidos afetivo-emocionais da experiência de ter convivido com um pai alcoolista ao longo da vida, realizamos uma pesquisa qualitativa psicanalítica. Foram realizadas entrevistas individuais com 12 filhos adultos, iniciadas por uma Narrativa Interativa (NI), usada como recurso investigativo que visa estabelecer um campo lúdico-ficcional para facilitar as associações livres dos participantes. Foi criada uma NI para este estudo, cuja trama se desenrola em torno da expectativa de um filho que aguarda a chegada do pai alcoolizado, momento em que a trama é interrompida para que o participante complete o seu desfecho. Como procedimento de registro, o pesquisador elaborou Narrativas Transferenciais que descrevem cada encontro e sua tonalidade afetiva. A análise interpretativa do material narrativo resultou em quatro campos de sentidos afetivo-emocionais: "Sua Majestade: o Alcoolista!" que descreve o lugar ocupado pelo pai na cena familiar; "Papai, quem é você?", campo que alude à experiência desorganizadora desencadeada pela imprevisibilidade ambiental; “Só me resta sobreviver!", o qual descreve as estratégias defensivas mobilizadas pelos filhos de alcoolistas; e “Desejo ter nas mãos a minha história!", que alude ao resgate de uma vida autêntica e dotada de sentido. As consequências nefastas do alcoolismo parental para a saúde mental dos filhos foram discutidas à luz da psicanálise winnicottiana, o que revelou um profundo sofrimento emocional que interpela os pesquisadores sobre práticas profissionais afinadas às necessidades dessa população.

Palavras-chave: Alcoolismo, Relações Pais-Filhos, Narrativa Interativa, Psicanálise.

\section{The Emotional Distress of the Children of Persons with Alcohol Use Disorder: A Winnicottian Psychoanalytic Perspective}

\begin{abstract}
The relationship between a person with alcohol use disorder and their children can be rather troubled in terms of domestic violence, moral disqualification, insecurity, and financial difficulties, leading to multiple dilemmas. This qualitative psychoanalytic research aims to assess the affective-emotional senses arising from the experience of having lived with a father who misuses alcohol. For that, 12 adults underwent individual interviews initiated by an Interactive Narrative (IN) as investigative resource, which established a ludic-fictional field for emotional expression aiming to enable participants' free associations. Through a plot constructed around a son expecting the arrival of a father with hazardous alcohol use, the participant is invited to conclude the IN. As registration procedure, the researcher elaborated transferential narratives describing each encounter and its respective affective tone. From an interpretive analysis, four fields of affective-emotional senses were identified in the narratives: "His Majesty: the Alcoholic!" which describes the place occupied by the father in the family; "Dad, who are you?" which alludes to the disorganizing experience triggered
\end{abstract}


by environmental unpredictability; "Surviving is all I have left!" which describes defensive strategies adopted by interviewers; and "I wish to hold my story on my own hands!" which alludes to the rescue of an authentic and meaningful life. The harmful consequences of parental alcohol abuse for children's mental health were discussed in the light of Winnicottian psychoanalysis, revealing a deep emotional distress that questions researchers about professional practices aimed at this population.

Keywords: Alcoholism, Parent-Child Relations, Interactive Narrative, Psychoanalysis.

\section{El Sufrimiento Emocional de Hijos de Alcohólicos: Un Entendimiento Psicoanalítico Winnicottiano}

Resumen: Lo hijos de alcohólicos sufren con dilemas provenientes de la relación conturbada con el progenitor alcohólico, como la violencia doméstica, la descalificación moral, la inseguridad y las dificultades financieras. Con el propósito de identificar sentidos afectivo-emocionales de la experiencia de haber convivido con un padre alcohólico durante la vida, realizamos una investigación cualitativa psicoanalítica. Se realizaron encuestas individuales a 12 hijos adultos, desencadenadas por una narrativa interactiva (NI), como recurso investigativo que pretende establecer un campo lúdico-ficcional para facilitar las asociaciones libres de los participantes. Se creó una NI para este estudio, cuya trama se desarrolla alrededor de la expectativa de un hijo que espera la llegada de un padre alcohólico, la cual se interrumpe para que el participante complete su desenlace. Como procedimiento de registro, el investigador elaboró narrativas transferenciales que describen cada encuentro y su tono afectivo. El análisis interpretativo del material narrativo dio como resultado cuatro campos de sentido afectivo-emocionales: “¡Su Majestad: el Alcohólico!”, describiendo el lugar ocupado por el padre en la familia; “Papá, ¿quién es usted?", aludiendo a la experiencia desorganizadora por la imprevisibilidad del entorno; “Solo me queda sobrevivir!”, describiendo estrategias defensivas movilizadas por los hijos de alcohólicos; “¡Deseo tener mi historia en las manos!”, aludiendo al rescate de una vida auténtica y dotada de sentido. Las consecuencias perjudiciales del alcoholismo de los padres a la salud mental de los hijos se discutieron a la luz del psicoanálisis winnicottiano, lo que demostró un profundo sufrimiento emocional que requiere de los investigadores prácticas profesionales ajustadas a las necesidades de esa población.

Palabras clave: Alcoholismo, Relaciones Padres-Hijos, Narrativa Interactiva, Psicoanálisis.

O alcoolismo é um problema de saúde pública que apresenta impactos psicológicos e sociais nas pessoas etilistas e em suas famílias (Carrol, Rhew, \& Larimer, 2019; Orford et al., 2019). Nesse contexto, a família do alcoolista enfrenta dificuldades em diversos âmbitos, sobretudo na esfera das responsabilidades de seus membros e na comunicação interpessoal (Haverfiel, Theiss, \& Leustek, 2015; Mangueira \& Lopes, 2014). Além disso, problemas como dificuldades financeiras, violência doméstica, desqualificação moral e comportamento imprevisível da pessoa dependente de álcool podem acarretar sofrimento emocional para seus familiares (Teixeira, Hoepers, Correa, Dagostin, \& Soratto, 2015).

No cotidiano dessas famílias que vivem relações interpessoais conflituosas e invasivas, os filhos experimentam os efeitos negativos no processo de subjetivação (Silvé Hamgstöm \& Forinder, 2019). A comunicação parental agressiva e autoritária, os tabus que instalam o silêncio sobre assuntos emblemáticos da convivência, a violência intrafamiliar e a intensidade e frequência da ansiedade e do medo perante as condutas do progenitor alcoolista são fatores que favorecem o sofrimento psíquico nos filhos, contribuindo para o 
desenvolvimento de transtornos psiquiátricos (Furtado, Laucht, \& Schmidt, 2002; Haverfiel et al., 2015; Pereira et al., 2015) e alterações cerebrais (Holla, Bharath, Venkatasubramanian, \& Benegal, 2019).

Após analisarem prontuários de psicólogos e psiquiatras estadunidenses, Hinrichs, De Fire e Wester (2011) elaboraram quatro categorias de personalidade dos filhos adultos de alcoolistas que cresceram em ambientes marcados pela violência e instabilidade emocional. O grupo dos filhos reativo-somatizantes se caracteriza pelo desenvolvimento de intensas respostas psicossomáticas perante os estressores ambientais. Os inibidos tendem a se isolar socialmente, evitando exposições que possam comprometer o equilíbrio emocional, sendo que traços de depressão são mais intensos nesta categoria. Os filhos de alcoolistas de alto funcionamento apresentam resultados acima da média nos estudos e no trabalho, embora vivenciem conflitos emocionais, particularmente no âmbito da autoestima. Finalmente, o grupo dos filhos externalizantes é composto por aqueles que desenvolvem traços antissociais, apresentando comportamentos violentos e, inclusive, tornando-se alcoolistas.

Omkarappa e Rentala (2019) avaliaram a ansiedade, a depressão e a autoestima entre filhos de dependentes de álcool e filhos de não-dependentes. Na comparação dos resultados, as autoras concluíram que o maior índice de sofrimento emocional é dos filhos de alcoolistas, fato que atribuem às experiências adversas vividas pelos participantes na infância. Lacopetti, Londi, Patussi, Sirigatti e Cosci (2019) chegaram a conclusão semelhante quando observaram que os filhos de alcoolistas apresentam níveis mais altos de ansiedade e depressão, além de estratégias de enfrentamento pouco eficazes.

Quanto à figura do pai e/ou mãe dependente de álcool, Albuquerque, Heimerdinger e Rodrigues (2016) notam uma visão dicotômica, na medida em que os filhos nos veem como pessoas boas quando estão sóbrios e más quando estão embriagados. Os relatos dos participantes comunicam sentimentos distintos quando se referem às lembranças do passado $\mathrm{e}$ às expectativas para o futuro, sendo que para alguns, a única possibilidade de resgate de uma vida autêntica e com sentido seria por meio da distância geográfica da família, enquanto para outros, cuidar do progenitor alcoolista faz parte de seus planos para o futuro.

Interessados em compreender a resiliência desse público, Silva, Silva e Vaz (2013) descreveram comportamentos e sentimentos dos filhos de dependentes de álcool no enfrentamento das dificuldades e na ressignificação das lembranças traumáticas. $\mathrm{O}$ temperamento afetuoso, a responsabilidade com o projeto de vida e as interpretações positivas sobre as experiências tendem a funcionar como características protetoras. Contudo, é a capacidade de se afastar das situações críticas vividas na família que permite que o filho elabore as experiências e crie condições subjetivas e objetivas para protagonizar a própria história.

Com o intuito de aproximar o leitor da experiência vivida por essa população, apresentamos o estudo de caso de Santos, Silva e Silva (2012) sobre uma filha adulta que cuida da mãe idosa e dependente de álcool. $\mathrm{Na}$ entrevista, a participante recorda o passado e suas experiências com o alcoolismo materno. A negligência parental, o desamparo emocional e a insegurança do cuidado foram vivências recorrentes desde a infância, que puderam ser contidas por familiares que assumiram parcialmente as funções materna e paterna. O relato dessa participante permitiu que as autoras discutissem a inversão de papéis e a assunção de responsabilidades que seriam destinadas à progenitora alcoolista.

Durante a adolescência, a participante do estudo de Santos et al. (2012) decidiu trabalhar para contornar as dificuldades financeiras e oferecer apoio para os irmãos menores. Na vida adulta, adquiriu novas habilidades, superando dificuldades, casando-se e constituindo família. Apesar da resiliência da participante, as autoras destacam a presença de um discurso ambíguo, o que alude aos impactos emocionais do alcoolismo parental em sua história de vida. É diante desse cenário de relações parentais marcadas pela ambivalência e intenso sofrimento, que o presente estudo tem como objetivo acessar os sentidos afetivo-emocionais da experiência de filhos adultos na convivência com o progenitor dependente de álcool.

\section{Métodos}

Stake (2011) argumenta que a abordagem qualitativa na pesquisa possibilita a compreensão das experiências e significados humanos e que, diferentemente dos métodos quantitativos que adotam a perspectiva sujeito-objeto, fundamenta-se na perspectiva intersubjetiva, que defende a descrição e a análise da interação pesquisador-participante como partes da complexidade do fenômeno investigado. Como nosso objetivo é compreender os sentidos 
afetivo-emocionais da convivência dos participantes com seus progenitores dependentes de álcool, na singularidade e no contexto em que essa experiência se produz, optamos pela pesquisa qualitativa que faz uso do método psicanalítico (Aiello-Fernandes, Ambrosio, \& Aiello-Vaisberg, 2012).

O método psicanalítico, que é usualmente associado ao tratamento psicanalítico, mas que não se resume a sua terapêutica, comporta uma vertente investigativa e seu uso sobre o material de pesquisa potencializa a emergência de sentidos inconscientes (Herrmann, 2004). Herrmann (1979/2001) enumera passos para o uso do método psicanalítico na pesquisa: no primeiro, o pesquisador se permite impressionar pela transferência e contratransferência, compreendendo as tonalidades emocionais do fenômeno investigado. No segundo passo, o pesquisador seleciona um tema da experiência emocional para analisar. No terceiro e último passo, o pesquisador se debruça sobre o tema selecionado buscando alcançar uma compreensão em profundidade sobre o fenômeno.

Fundamentados nas reflexões de Politzer (1928/1998) sobre a prática psicanalítica poder se basear na experiência concreta do indivíduo, e não em construções metapsicológicas sobre o psiquismo, elegemos Winnicott como nosso principal interlocutor, à medida que propõe uma psicanálise concreta. Esse posicionamento epistemológico se apoia no valor heurístico das ideias winnicottianas para a compreensão da experiência vivida, cuja abordagem fenomenológica se distancia tanto de um positivismo empobrecedor como de uma psicanálise especulativa.

Para a concretização desta pesquisa, contamos com a mediação dos Grupos Familiares de Alcoólicos Anônimos (AL-Anon) do Brasil. Os grupos AL-Anon estão presentes em todo o território nacional, realizando encontros de ajuda mútua entre familiares de alcoolistas por meio de literatura própria, como folders, livros e programações de atividades. Dentre seus membros, 12 filhos de alcoolistas maiores de 18 anos se voluntariaram a colaborar com este estudo, sendo três homens e nove mulheres, cujas idades variam entre 21 e 66 anos. Os participantes passaram por entrevistas individuais em duas etapas: na primeira, apresenta-se o recurso investigativo da Narrativa Interativa (NI) (Granato \& AielloVaisberg, 2013), história ficcional construída em torno do tema a ser investigado, mas que se interrompe como convite para que o participante a complete, elaborando seu desfecho. Em seguida, o participante é convidado a associar livremente o drama enunciado pela NI para que, de forma lúdica, seja estimulado a comunicar sua experiência pessoal. Objetiva-se, dessa forma, acessar substratos afetivo-emocionais da experiência narrada, caracterizando-se, portanto, como um recurso apresentativo-expressivo (AielloVaisberg, 2004), tal como o Jogo do Rabisco de Winnicott (1984), que convidava seus pacientes a se expressarem pela via do desenho interativo. A seguir, apresentamos a NI criada para este estudo:

Era noite e Gilberto estava em seu quarto estudando, revendo as anotações que tinha feito das aulas do curso técnico. Sentia-se animado com as aulas e enquanto lia os textos e refazia os cálculos matemáticos, escutava as músicas que tocavam em seu rádio. Às vezes, ao som da música, Gilberto devaneava, recordando-se do que tinha lhe acontecido durante o dia. Tantas pessoas importantes que tinha conhecido recentemente... Fazia projetos para o futuro e se imaginava em novas situações e experiências.

- Mas que fome!!! - pensou o rapaz. Fazia horas que não se alimentava em função da dedicação aos estudos. Nesse momento, dirigiu-se à cozinha para jantar, mas antes passou pela sala, onde estava a sua mãe, Maria Amélia. Gilberto viu a mãe sentada no sofá, tranquila, assistindo à televisão. Depois, pegou um prato na cozinha e começou a explorar o que tinha no fogão, ficando surpreso e bem contente com a carne de panela com batata.

De repente, a cachorra começou a latir e Gilberto se lembrou de que seu pai, Osvaldo, estava fora de casa, bebendo. Será que ele chegou?! - pensou o moço, apreensivo. Naquela hora, Maria Amélia se levantou do sofá e foi até a cozinha, ao encontro do filho. Gilberto conhecia aquela expressão no olhar da mãe.... Sim, Osvaldo tinha acabado de chegar em casa, estacionando o carro em cima da calçada.

Gilberto percebeu seu coração mais acelerado e, deixando o prato na mesa da cozinha, acompanhou a mãe até a entrada da casa para receber o pai. Quando Gilberto abriu a porta...

Inspirados em Winnicott (1984), compreendemos que a NI é o primeiro rabisco do pesquisador que convida o participante para a espontaneidade do próximo 
rabisco, estabelecendo o diálogo como forma de comunicação na pesquisa. Como procedimento de registro, o pesquisador redigiu Narrativas Transferenciais (NT), que visam descrever o encontro em suas tonalidades afetivas (Aiello-Vaisberg, Machado, Ayouch, Caron, \& Beaune, 2009). O material narrativo composto pelas NI e NT foi analisado interpretativamente por meio do método psicanalítico (Herrmann, 1979/2001) que resultou na elaboração de quatro campos de sentidos afetivo-emocionais (Politzer, 1928/1998) que comunicam a experiência emocional de filhos de alcoolistas. Finalmente, destacamos que o presente estudo foi aprovado pelo Comitê de Ética em Pesquisa com Seres Humanos da Pontifícia Universidade Católica de Campinas sob o registro 2.396.129. Os participantes foram devidamente informados sobre os objetivos e métodos da pesquisa, tendo assinado o Termo de Consentimento Livre e Esclarecido após a decisão de participar do estudo. Foram atribuídos nomes fictícios aos participantes com o intuito de preservar o sigilo e o anonimato.

\section{Resultados e discussão}

Como resultado da análise interpretativa do material narrativo, chegamos a quatro campos de sentidos afetivo-emocionais que comunicam o drama vivido por filhos de alcoolistas: "Sua Majestade: o Alcoolista!", "Papai, quem é você?", "Só me resta sobreviver!" e "Desejo ter nas mãos a minha história!". Cada campo é constelado em termos dramáticos, atendendo à proposta de uma psicanálise concreta (Bleger, 1963/1984; Politzer, 1928/1998) que se baliza pela vivência do participante e não pela teoria adotada. Ressaltamos que os campos de sentidos afetivo-emocionais são elaborados por meio do debate do pesquisador com seu grupo de pesquisa, tomando como objeto de análise os conteúdos manifestos e latentes dos relatos, bem como os processos contratransferenciais que permeiam toda entrevista. Durante as discussões, também analisamos o potencial da NI na criação de um ambiente lúdico-ficcional capaz de acolher a criatividade e a expressão emocional dos participantes quando compartilham suas experiências pessoais com o pesquisador.

\section{Campo 1: Sua majestade: o Alcoolista!}

O presente campo comunica a experiência de submissão vivida pelos filhos diante dos desejos do pai alcoolista, salientando que, no caso dos entrevistados, somente a figura paterna foi descrita como dependente de álcool. Os relatos dos participantes descrevem sua experiência de convivência com um pai que está sempre no "centro das atenções", demandando a adaptação dos filhos e da esposa, que passam a orbitar em torno dele. Observamos que nessa relação parental em que impera a submissão, a espontaneidade dos filhos é inibida e, consequentemente, também a vida criativa e autêntica, tal como foi teorizada por Winnicott (1971/1975).

O lugar de majestade fica reservado ao pai alcoolista, cujo poder se impõe pela violência, instaurando ansiedade e medo nos filhos, que são subjetivamente invadidos pelas demandas paternas. De modo análogo a um rei despótico, o pai alcoolizado não reconhece a alteridade daqueles com quem convive, tratando-os como servos. Essa convivência diária com um ambiente familiar invasivo gera sentimentos de humilhação, desamparo e raiva, como o participante Gabriel descreveu após episódios de desqualificação moral do pai contra os filhos.

As NT das entrevistas e os desfechos escritos pelos participantes para a NI revelam esse contexto familiar de sofrimento (Mangueira \& Lopes, 2014), no qual o pai controla a família pelo medo. Mariana explica o tipo de sofrimento vivido na presença de um pai abusivo:

Mariana percebia que sua família "vivia uma loucura" (sic) e que se não tomasse cuidado poderia enlouquecer com eles. Foi se cansando daquela repetição eterna do álcool. Começou a ter medo de um dia se ver desse jeito, bebendo intensamente. Conseguia ver esse movimento no próprio pai, um homem com o qual nunca pôde ter uma conversa honesta sobre os seus sentimentos. Nessa relação, o afeto era escasso, faltava assunto para um diálogo, assim como um interesse livremente motivado para conversar. O que restava quando se encontravam? Para Mariana é difícil descrever o que sente, mas sabe que se incomodava com os comportamentos abusivos do pai, principalmente quando este exigia que os familiares o servissem como, por exemplo, entregando-lhe em mãos um prato de comida feito. Para a jovem, o alcoolismo favorece relacionamentos abusivos e os comportamentos do dependente que caminham para esse funcionamento a irritam. (NT, Mariana) 
A participante Joana criou em sua NI um desfecho para o personagem Gilberto no qual o filho se submete às imposições de um pai majestade:

Todos estavam na mesa e as confusões começaram. Gilberto empurrava para o canto do prato partes da comida que não gostava e o pai, vendo esse comportamento, começou a reclamar. Gilberto, então, comeu sem nada dizer, mas aquela comida desceu machucando o seu esôfago. Além disso, àquela altura, ela estava fria e Gilberto não gostava de comida gelada. Maria Amélia, muda, permaneceu muda. O pai tentou puxar um assunto para enaltecer o filho, mas com aquele clima Gilberto não conseguia sequer responder. De repente, o pai começou a gritar, mandando que o filho comesse mais rápido, afinal, demorava muito para terminar a refeição. Poucos minutos depois, um prato de comida voou na cara do jovem. Gilberto caiu no chão e Maria Amélia avançou no marido, batendo no seu peito e dizendo que se o filho ficasse com problemas de visão ele iria se haver com ela. Mas, em todo esse tempo, o garoto estava ainda no chão, sem ser socorrido pela mãe. Osvaldo deitou no sofá e em minutos estava dormindo e a mãe permaneceu num canto, chorando copiosamente. Engolindo o choro e sem fome, o filho se limpou e foi para o banheiro da casa, trancando-se. Lá, sozinho, ficou imaginando histórias de como poderia ser a sua vida no futuro! Era como se ele entrasse em um outro mundo ou dimensão. E lá permaneceu por um bom tempo. (NI, Joana)

O desfecho da NI de Joana descreve um ambiente familiar instável, violento e humilhante. Na cena em que Gilberto é agredido e cai no chão, observamos que a mãe não socorre o filho, mas dirige-se ao pai, ameaçando-o com a força de sua indignação. Assim, fica evidente que o foco das atenções é o pai alcoolista, enquanto mãe e filho têm suas necessidades negligenciadas.

Essa experiência de desamparo vivida pelos filhos em função da prioridade que sua família dá às demandas do pai dependente de álcool é descrita por Woodside (1988) como uma característica das famílias de alcoolistas. Entretanto, uma questão aqui se apresenta: por que razão esse pai assume o lugar de majestade no seio familiar?
Podemos discutir que fatores históricos, sociais e culturais contribuam para o fortalecimento do lugar ocupado pelo pai dependente de álcool. Nesse sentido, homens que foram culturalmente educados com base no discurso patriarcal e machista podem desenvolver condutas autoritárias com os homens mais jovens e, principalmente, com as mulheres (Aguiar, 2000; Beauvoir, 1949/1967; Beauvoir, 1949/1970). Há que destacar que embora o lugar de "majestade" tenha sido usurpado historicamente pelos homens na sociedade, no contexto do alcoolismo, esse fenômeno se torna potencializado pelo impacto do álcool nas funções psíquicas do indivíduo, tornando-o menos crítico e ético.

A condição de majestade do pai alcoolista também pode ser compreendida por meio de estudos da psiquiatria. Malbergier e Cardoso (2011) consideram que os transtornos associados ao uso de substâncias (Taus) podem estar relacionados aos transtornos de personalidade (TP). Os autores trabalham com a hipótese de haver uma relação entre o humor/ personalidade do dependente químico e os transtornos de personalidade antissocial e borderline. Portanto, há uma possibilidade de que esse lugar de soberania sobre os demais familiares seja engendrado por conflitos psicológicos e psiquiátricos já vividos anteriormente pelo alcoolista.

De nossa parte, podemos elaborar uma compreensão winnicottiana a respeito dessa posição familiar assumida pelo progenitor dependente de álcool. Abram (2000) defende que, diferentemente do narcisismo primário freudiano, no narcisismo winnicottiano a imaturidade do bebê convoca a mãe-ambiente para o exercício de cuidados. Trata-se de uma adaptação subjetiva realizada pela mãe e/ou outro cuidador que cumpra esse papel, denominada de Preocupação Materna Primária (Winnicott, 1956/2000), que possibilita que a mulher e/ou outra pessoa exerça o cuidado físico e emocional adaptado às necessidades do bebê.

A concepção de Winnicott (1956/2000) sobre a necessidade de o ambiente humano prover cuidados para um indivíduo imaturo se mostra particularmente adequada para a compreensão da dinâmica familiar alcoolista. Nos relatos dos participantes, observamos que o progenitor dependente de álcool apresenta condutas impulsivas e imaturas, mobilizando os familiares, incluindo os filhos, a atuarem inconscientemente como a mãe-ambiente preconizada por Winnicott em sua adaptação ao bebê. Observamos no desfecho da NI de Joana tal movimento, no qual a prioridade de cuidados é destinada ao pai: 
Ele [Osvaldo] entrou em casa e Maria Amélia o recebeu perguntando:

-Você quer comer ou tomar um banho?

Osvaldo disse que queria comer e então a esposa preparou a mesa de jantar. Tirou o prato frio de Gilberto que estava esquecido na cozinha e o esquentou na frigideira. E, quando o filho foi para a cozinha, aproveitou para lhe dizer que a carne de panela era suficiente para os três; porém, o pai precisava de uma parte maior por ser o trabalhador da casa. Naquele jantar, Gilberto ficou com mais batata do que carne em seu prato... (NI, Joana)

A conduta dos familiares nos parece compor um quadro de Preocupação Familiar Primária, visto que o alcoolista se torna o "centro das atenções", tal como o bebê o é para a mãe devotada comum (Winnicott, 1956/2000). Contudo, diferentemente da adaptação materna que acompanha o crescimento do bebê, a Preocupação Familiar Primária engendrada pelo alcoolismo não se desenvolve rumo a seu desfecho, já que o "bebê-alcoolista" não amadurece.

Compreendemos que essa impossibilidade de desfecho temporal para a dependência que se estabelece entre os membros da família configura uma prisão afetivo-emocional, em que todos se sentem convocados emocionalmente a cuidar da pessoa etilista. Assim, supomos que a Preocupação Familiar Primária somada à conduta autoritária e violenta do pai alcoolista fortalecem o lugar de majestade ocupado pelo progenitor, ainda que de forma temporária, na medida em que o ocupa quando está alcoolizado.

Além disso, podemos supor que a esse acesso temporário a um lugar de ascendência sobre o outro subjaz uma realidade oposta, em que o progenitor ocupa um lugar social de não reconhecimento, de não-existência, sendo o álcool sua única possibilidade de ser alguém. Contudo, ainda que compreendamos os dilemas existenciais e sociais do alcoolista, o impacto emocional dessa dinâmica familiar sobre os filhos fica evidente no desfecho que Alfredo dá para sua NI.

O pai perguntou sobre a janta para ele [Gilberto] e ela [Maria Amélia] submissa foi preparar um prato. Ao sentar-se na mesa Osvaldo imediatamente começou a reclamar que aquilo não era janta para um pai de família trabalhador.

A mãe tentou intervir e dialogar, mas o pai agressivamente jogou a alimentação no lixo. A mãe alegou que ele estava alcoolizado e alterado, mas ele respondeu que quem pagava a bebida era ele e que não dependia ou pedia nada a ninguém.

Gilberto já traumatizado pelo frequente embriagar do pai se pôs a intermediar a discussão tentando neutralizar a agressividade do pai e a angústia da mãe; ele tentou absorver toda a situação como se fosse dele.

Diante da frequente experiência de intrusão ambiental promovida pelo pai majestade, observamos a estruturação de defesas psíquicas pelos filhos, com o objetivo de garantir sua sobrevivência emocional e, consequentemente, preservar o verdadeiro self (Winnicott, 1960/1990, 1963/1994). Assim, concluímos que a submissão ao ambiente invasivo alcoolista inibe o gesto espontâneo, comprometendo a continuidade existencial e a possibilidade de viver uma vida autêntica (Winnicott, 1958/1993, 1971/1975).

\section{Campo 2: Papai, quem é você?}

Este campo de sentidos revela a experiência emocional dos participantes com a imprevisibilidade do comportamento paterno. Seus relatos apresentam dois aspectos da imprevisibilidade parental que desencadeiam ansiedade, sendo o primeiro referente às expectativas familiares quanto a condutas impulsivas e violentas do pai, caso este chegue em casa alcoolizado.

Após escrever um desfecho para a NI em que o personagem Gilberto atende às necessidades do pai $\mathrm{e}$ da mãe sem sobressaltos, o participante Gabriel pontua que as suas experiências nesse aspecto foram completamente diferentes do final retratado em sua NI: "Parece que aí ele [Gilberto] está em paz, estudando e distraído! Não foi assim que eu vivi quando meu pai chegava em casa! Era ansiedade pura e eu ficava muito mal, com medo e nervoso". Com uma experiência semelhante, a participante Rosa descreve o medo diante da imprevisível chegada do pai em casa, momento carregado de expectativas de violência:

Na minha casa, o alcoolista era o meu pai, e ele bebeu desde que eu me conheço por gente. A questão é que ele saía muito para ir ao bar... quase todos os dias e eu e minhas irmãs tínhamos muito medo do momento em que ele chegaria em casa, pois geralmente víamos cenas de violência em que ele era o agressor. Horrível! Meu principal 
terror, assim como das minhas irmãs, era chegar em casa e deparar com ele espancando a nossa mãe. Nós já vimos isso e ficamos desesperadas! Numa das ocasiões, totalmente paralisadas, e não sabendo o que fazer para impedir aquilo, ficamos chorando uma noite inteira. (Rosa)

O segundo aspecto da imprevisibilidade paterna se refere à oscilação entre o que os participantes chamaram de uma "dupla personalidade" do pai alcoolista: quando está sóbrio apresenta humor estável e capacidade para o diálogo, mas, quando alcoolizado, tende a apresentar comportamentos impulsivos e violentos. A NT de Vanessa descreve a presença desse pai que apresenta duas personalidades, as quais a participante busca compreender e conter imaginativamente através da religião:

Vanessa recordava da figura paterna como um homem de duas personalidades: na primeira, uma pessoa tranquila e, na segunda, alguém que ficava irreconhecível quando exibia condutas agressivas. Neste ponto, a participante trouxe uma nova lembrança: ela, menina, na missa, durante a fila da Santa Comunhão. Ao receber a hóstia consagrada do padre, ajoelhou-se em seu banco e, em oração, conversou com Jesus: "Senhor, que meu pai não beba hoje! Senhor, que exista paz em nossa casa! (NT, Vanessa)

Diante da imprevisibilidade da conduta paterna, supomos que o filho de alcoolista permaneça em um estado de alerta para a possibilidade de novas vivências traumáticas, vivendo a dúvida sobre quem é, de fato, o seu pai: o homem sóbrio e capaz de conversar ou o homem alcoolizado que age de forma impulsiva e violenta? É com essa questão emergente de nossa contratransferência que chegamos a este segundo campo de sentidos: "Papai, quem é você?". Fundamentados na teoria da provisão ambiental de Winnicott (1962/1990), compreendemos que essa dúvida sobre a figura paterna revela falhas ambientais, destacando-se a imprevisibilidade que compromete o estabelecimento de uma relação de confiança entre as pessoas.

Winnicott (1969/1993) argumenta que a previsibilidade do cuidado materno é fundamental para o desenvolvimento emocional do bebê. A rotina de cuidados exercida pela mãe e/ou outro cuidador que cumpra esse papel assegura um ambiente estável e previsível, capaz de sustentar o sentimento de continuidade de ser da criança, o que possibilita a construção do sentimento de confiança no ambiente. De acordo com o autor, o ambiente imprevisível produz sofrimento emocional, visto que lança o bebê em agonias impensáveis contra as quais precisa se defender, reagindo.

Inspirados nas reflexões de Winnicott (1962/1990; 1969/1993), compreendemos que as narrativas dos participantes descrevem experiências marcadas pela imprevisibilidade ambiental, produzindo intensas ressonâncias emocionais e comprometendo a estruturação de um sentimento de confiança no ambiente familiar. Essa desconfiança básica, que defensivamente se organiza para conter o impacto emocional do ambiente imprevisível, parece-nos comprometer a espontaneidade e o viver autêntico dos filhos.

Ressaltamos que além da confiança, a previsibilidade ambiental estrutura o sentimento de segurança (Winnicott, 1960/1993b), que é imprescindível para que o indivíduo se desenvolva de modo saudável. Contudo, nos ambientes imprevisíveis, a insegurança e a desconfiança contribuem para que o desenvolvimento emocional ocorra de modo distorcido, pois, em resposta às falhas da provisão ambiental, o psiquismo tende a estruturar defesas.

Deve existir no íntimo de cada criança uma crença em algo; não só algo que é bom, mas algo que é confiável e duradouro, ou que se recupera depois de ter sido magoado ou de se ter consentido que perecesse .... Neste ponto, porém, quero referir-me à contribuição ambiental, o papel que desempenhamos e o papel que a sociedade desempenha em relação a nós. É o meio circundante que possibilita a cada criança crescer, e sem adequada confiabilidade ambiental o crescimento pessoal de uma criança não pode acontecer, ou será um crescimento distorcido (Winnicott, 1960/1993b, pp. 102-103).

As participantes Vanessa e Alessandra também descreveram a experiência com um ambiente familiar imprevisível e violento que impediu o pleno desenvolvimento dos sentimentos de confiança e segurança. Vanessa, por exemplo, descreve um pai alcoolizado que destrói a casa nos momentos de fúria, deixando os familiares amedrontados. 
Se as portas falassem, elas diriam muito sobre o medo que eu, minhas irmãs e minha mãe passamos em casa! Nossa, cada situação! Meu pai chegava bêbado, provocava brigas e quebrava pratos, copos e xícaras! Ele xingava a gente, sem motivo, e muitas vezes conseguiu comprar armas e punhais nos bares. Eu ficava horrorizada e com muito medo! (Vanessa)

Na experiência de Alessandra, destacam-se cenas de terror, pois o pai alcoolizado ameaçava todos da casa com uma faca na mão.

Ocorriam muitas brigas na família, mas na hora da confusão a minha mãe gritava para que saíssemos correndo de casa porque ele tinha uma faca na mão e vinha da cozinha dizendo que iria nos matar. Nossa, meu Deus! A gente ficava em choque e saía correndo no meio da rua, com medo e pensando na mãe, ali sozinha com ele! (Alessandra)

Destacamos que as frequentes intrusões ambientais promovidas pela imprevisibilidade do progenitor alcoolista podem estabelecer dinâmicas defensivas nos filhos que, em última análise, objetivam proteger o verdadeiro self. Nessas vidas que foram marcadas por um ambiente de constante imprevisibilidade, a confiança pode ter sido destruída para sempre...

Hoje eu sinto dificuldade em aceitar um 'eu te amo' como uma expressão sincera! Sinto que ela é aprendida pelas pessoas, não autêntica, entende? O 'eu te amo' ficou banalizado, todo mundo fala sem pensar direito no que fala... Portanto, para mim as pessoas podem ser amigas, mas não que isso signifique que elas amem no sentido forte da palavra! (Joana)

Concluímos a reflexão deste campo de sentidos afetivo-emocionais retomando a questão que o inaugura: quem é esse pai? Ainda que a figura paterna se mantenha ambígua, observamos nas narrativas dos participantes a existência de uma teoria implícita sobre a personalidade do progenitor. Segundo ela, o pai alcoolista é concebido como detentor de duas personalidades: uma verdadeira e uma falsa. A falsa seria a personalidade alcoolista, marcada pela violência e imprevisibilidade, enquanto a verdadeira seria a figura do pai sóbrio e sociável. Segundo essa crença, o alcoolismo aprisionaria subjetivamente o "pai verdadeiro", enquanto o "pai falso" dominaria e controlaria a cena familiar.

Essa teoria implícita também foi identificada por Aguiare Menandro (2012) em esposas de alcoolistas que nutrem a esperança de que, no futuro, o companheiro abandone o consumo de álcool. Essa esperança nos parece revelar tanto a necessidade de um ambiente previsível, seguro e confiável, tal como preconizado por Winnicott (1962/1990, 1969/1993), como o receio de jamais encontrar o cuidado suficientemente bom. A fantasia de que existe um pai bom acuado por um pai mau e dominador pode ter sido alimentada já na infância dos participantes como teoria explicativa que tornava a realidade familiar tolerável. Nutrir a esperança de que o bom pai será um dia resgatado pode aqui ser compreendido como construção de um porto seguro em torno do qual a criança pode se desenvolver emocionalmente e proteger o núcleo do self.

\section{Campo 3: Só me resta sobreviver!}

O presente campo de sentidos afetivo-emocionais se organiza em torno da necessidade dos filhos de alcoolistas de desenvolverem recursos e/ou defesas psíquicas para sua sobrevivência emocional diante das falhas de cuidado e proteção do ambiente familiar. Observamos quatro estratégias defensivas mobilizadas pelos participantes a fim de conter as intrusões ambientais e recuperar o sentimento de continuidade de ser.

Amadurecer precocemente se destacou como uma das estratégias utilizadas por esse público, visto que, diante da instabilidade familiar e financeira, os filhos acabam assumindo responsabilidades parentais. Fernando descreve, em sua entrevista, os percalços da experiência de se tornar adulto antes do tempo.

Por ser o irmão mais velho e pela impossibilidade do meu pai colocar dinheiro dentro da própria casa para pagar as contas, eu fui obrigado, pelas circunstâncias da vida, a me tornar o homem da casa! Minha mãe me escolheu para tal tarefa, eu a ajudava a resolver problemas e, em certa medida, até a criar os meus irmãos mais novos. Aprendi cedo o sentido da palavra responsabilidade e, com ela, amadureci... Foi difícil, mas era o necessário! Sabe, o alcoolista só pensa na bebida, em como beber mais e permanecer bebendo... e o resto é o resto! Tanto faz as contas e os com- 
promissos assumidos, o que realmente importa é o álcool. E a gente que é da família percebe que está em um barco em alto mar, mas que ele está à deriva! E nessa situação a gente fica pensando: meu Deus, o que é que eu vou fazer? (Fernando).

Winnicott (1960/1993b) alerta contra os perigos do amadurecimento precoce, quando o indivíduo tende a sobreviver emocionalmente, distanciando-se do viver espontâneo. Vale ressaltar que a maturidade é sinônimo de saúde mental somente quando acompanha o ritmo do desenvolvimento emocional do indivíduo, sem os sobressaltos das intrusões que interrompem o viver e convocam reações/defesas.

A corrente psicológica a que me filio considera a maturidade sinônimo de saúde. A criança de dez anos que é saudável é madura para sua idade; o infante sadio de três anos tem a maturidade de um infante de três anos; $o$ adolescente sadio é um adolescente maduro, e não um adulto precoce. O adulto sadio é maduro enquanto adulto, o que significa que já transpôs todos os estágios de imaturidade, isto é, todos os estágios maduros anteriores. $\mathrm{O}$ adulto maduro tem a seu dispor todos os estados passados de imaturidade, e pode fazer uso deles por necessidade, por diversão, nas experiências secretas de autoerotismo ou nos sonhos (Winnicott, 1960/1993a, p. 129).

Um segundo recurso defensivo utilizado pelos participantes é a experiência de falso self, que se por um lado possibilita os ganhos do enfrentamento de dificuldades e angústias desorganizadoras, por outro inviabiliza a expressão do gesto espontâneo, roubando do indivíduo o sentimento de estar vivo e real (Winnicott, 1960/1990). Salientamos que o falso self se organiza como estratégia protetora do verdadeiro self diante de ambientes percebidos como não-confiáveis para a expressão autêntica do eu. Dessa forma, o verdadeiro selffica latente, à espera de um ambiente seguro e confiável para se manifestar, enquanto o falso self ganha tempo se submetendo às demandas do ambiente.

Ampliar a convivência com pessoas significativas que se apresentem como suporte confiável pode ser compreendida como uma terceira estratégia de sobrevivência emocional mobilizada pelos participantes, sendo as figuras da mãe, da avó e do avô referidas como alternativas ao pai alcoolista. A previsibilidade $\mathrm{e}$ a confiabilidade que caracterizam tais relações permitem o desenvolvimento de sentimentos de segurança e confiança, que são imprescindíveis para a estruturação e manutenção da saúde mental. Notamos que, apesar das falhas engendradas pelo alcoolismo paterno, o holding oferecido pelas figuras substitutivas de referência tende a amortecer a imprevisibilidade e a impulsividade paterna. Mariana, por exemplo, elege a avó como figura parental em sua vida:

Primeiramente, minha avó tinha uma cabeça aberta, ela era antenada com o que estava acontecendo no mundo. Não era alguém parado no tempo, entende? Tudo na casa dela era bom! A casa era maior, mais arejada, tinha comida boa, sucos e água fresca. Uma casa limpa, super organizada. Nossa! Estar lá era tudo de bom! Muito gostoso, mesmo! Eu me sentia bem! (Mariana).

O confronto com o pai alcoolista é outra estratégia utilizada pelos participantes. O impacto da violência paterna mobiliza os filhos a reagirem questionando e/ou agredindo o progenitor, com o objetivo de escapar de seu controle. Gabriel, por exemplo, fazia uso da racionalização nos seus confrontos com o pai alcoolizado com o objetivo de conter as agressões paternas pela via da argumentação.

O meu jeito de lidar era reagir ao meu pai! Não tinha saída, aquele era o meu jeito: reagindo. Cada irmão aprendeu uma forma e essa foi a minha. Discutia com ele, me colocava com argumentação e não deixava barato! Não permitia que toda aquela violência verbal ficasse apenas em mim, porque eu a distribuía nele. Eu o corrigia e mostrava que tinha conhecimento sobre a vida! (Gabriel).

Finalmente, destacamos a existência de uma constante vigília dos filhos de alcoolistas sobre o clima emocional do lar, buscando mantê-lo o mais harmonioso possível para evitar novas discussões. Essa conduta serve aos objetivos do falso self que, ao mesmo tempo que oculta o verdadeiro, procura condições para que este venha a se expressar futuramente quando o ambiente o permitir. Além disso, indica um medo inconsciente do colapso das defesas erigidas para a contenção das angústias que foram engendradas pela imprevisibilidade na relação parental (Winnicott, 1963/1994). 


\section{Campo 4: Desejo ter nas mãos a minha história!}

Este campo de sentidos traduz o desejo de viver a própria história de modo criativo e autêntico, isto é, não submisso. Os participantes descrevem projetos pessoais nos quais delineiam o resgate de uma vida ainda não vivida, através de mudanças nas relações interpessoais, a estruturação de novos lares nos quais se sentem seguros, novas profissões e/ou empregos e a busca de autoconhecimento, que lhes permitiram recuperar o viver criativo (Winnicott, 1971/1975).

O relato de Mariana ilustra a inibição do viver criativo, decorrente do fato de ter vivido submetida às demandas e imposições da família, principalmente do pai alcoolista. Mariana descreve que não sentia ânimo para qualquer manifestação espontânea e se deixava levar pelos acontecimentos cotidianos. Contudo, notou que quando se mudou de cidade e se afastou do ambiente familiar e sua envolvente dinâmica transferencial, pôde se redescobrir retirando o denso véu que ocultava o verdadeiro self.

Se na casa do meu pai me mandassem vestir uma calça amarela, ou de qualquer outra cor, eu vestia porque lá eu não escolhia as coisas para mim. Aqui é diferente, aqui eu escolho as cores que desejo vestir! Escolho para onde eu vou e o que desejo fazer. Sinto-me livre e viva! Vejo sentido no meu trabalho e nas minhas atividades e desejo viver! (Mariana).

A inibição do viver criativo é um fenômeno também referido por Vanessa quando se recorda das tristes festas familiares:

Vanessa descreveu que, durante a infância e a adolescência, o alcoolismo paterno transformou datas festivas como Natal, Ano Novo, Páscoa e férias em momentos tristes, sem brilho e sem cor. Nestas datas, o pai alcoolizado provocava brigas, situações de humilhação e um clima emocional pesado, deixando todos à mercê de suas vontades. O gosto por essas datas festivas foi recuperado somente após o casamento de Vanessa e o nascimento de seus filhos, trazendo um novo colorido para suas experiências. Sublinhou que o marido foi uma pessoa importante nesse processo, mostrando-lhe outros caminhos de interpretação da vida (NT, Vanessa).
Em função da prisão afetivo-emocional em que vivem os familiares do alcoolista, mobilizados pela Preocupação Familiar Primária, os participantes referem a distância geográfica como única solução que preserva o direito à privacidade, o verdadeiro self e a continuidade de ser. Nesse sentido, o estabelecimento de novas relações interpessoais proporcionou a Mariana e Vanessa o ambiente emocional necessário para que recolocassem em marcha o processo de integração psíquica das experiências vividas. Substituindo a dinâmica disfuncional da família alcoolista (Mangueira \& Lopes, 2014), as participantes puderam contar com uma nova rede de apoio capaz de prover suas necessidades e a retomada do processo criativo (Winnicott, 1971/1975).

Apesar de Gabriel e Michele morarem nas cidades de seus respectivos pais, a estruturação de um novo lar foi descrita por eles como uma questão de saúde mental. Nesse novo ambiente que é suficientemente bom, na medida em que acolhe o gesto espontâneo, as defesas contra intrusões ambientais se tornam desnecessárias e são gradativamente abandonadas em prol da vida criativa, que assim adquire um sentido pessoal (Winnicott, 1971/1975, 1960/1990).

Podemos destacar outras condutas criativas mobilizadas pelos filhos adultos de alcoolistas que objetivam assegurar o sentimento de continuidade existencial e a expressão da espontaneidade. Rosa, por exemplo, começou uma nova vida profissional na mesma área em que o pai trabalhava. A participante explicou que era frequente que o progenitor bebesse no emprego e que chegou a ser socorrido pelos funcionários da empresa por ocasião de um coma alcoólico. Recém-formada, Rosa compartilha com o pai os desafios que a nova profissão ensejava, conseguindo aproximar-se afetivamente do progenitor, apesar das cenas de violência que testemunhou em sua infância. A experiência de Rosa parece aludir às tentativas criativas encontradas por filhos de alcoolistas para se aproximarem de seus pais, buscando o restabelecimento do vínculo de confiança (Winnicott, 1960/1990, 1960/1993b, 1969/1993) precocemente rompido pelo alcoolismo.

Observamos na entrevista com Selma outra conduta criativa que visa a manutenção da saúde mental e a recuperação do gesto espontâneo. A participante fez psicoterapia e, com o auxílio da terapeuta, pôde compreender os impactos do alcoolismo paterno em suas emoções. Selma descreveu 
o autoconhecimento como uma ferramenta útil para a interpretação do que acontecia em sua vida, favorecendo a integração psíquica e restabelecendo o sentido de sua história.

As experiências dos participantes reverberam a compreensão de Winnicott (1971/1975) sobre o valor de viver uma vida protagonizada pelo verdadeiro self, após anos de submissão durante a infância e a adolescência.

É através da apercepção criativa, mais do que qualquer outra coisa, que o indivíduo sente que a vida é digna de ser vivida. Em contraste, existe um relacionamento de submissão com a realidade externa, onde o mundo em todos os seus pormenores é reconhecido apenas como algo a que ajustar-se ou a exigir adaptação. A submissão traz consigo um sentido de inutilidade e está associada à ideia de que não vale a pena viver a vida. Muitos indivíduos experimentaram suficientemente o viver criativo para reconhecer, de maneira tantalizante, a forma não criativa pela qual estão vivendo, como se estivessem presos à criatividade de outrem, ou de uma máquina. Essa segunda maneira de viver no mundo é identificada como doença, em termos psiquiátricos. De uma ou de outra forma nossa teoria inclui a crença de que viver criativamente constitui um estado saudável, e de que a submissão é uma base doentia para a vida (Winnicott, 1971/1975, p. 95).

Concluímos que a busca pelo viver criativo anunciado por Winnicott (1971/1975) é um movimento de saúde psíquica que possibilita a ressignificação da vida. Diante de ambientes previsíveis e confiáveis, os participantes puderam reelaborar o vivido para constituir novos relacionamentos interpessoais. Apesar das cicatrizes emocionais, descreveram cenas de amor e perdão do pai alcoolista. O final do relato de Rosa comunica o que nos pareceu sua última tentativa de resgatar os significados do vínculo parental.

Percebi que nossa entrevista caminhava para o encerramento, quando Rosa selecionou uma imagem interessante para ilustrar a convivência atual com o pai. A participante e seu esposo conversavam, via Skype, com o pai de Rosa, alcoolizado, achando-o engraçado sem a dentadura. A participante brincou com o pai sobre a sua boca e ambos riram. O que mais surpreendeu Rosa foi o
"Eu te amo! Eu amo vocês!" dito de forma espontânea pelo pai. Para Rosa aquelas palavras eram preciosas como diamantes... (NT, Rosa).

\section{Considerações finais}

Destacamos que os quatro campos de sentidos afetivo-emocionais comunicam a experiência emocional dos participantes sobre a relação parental com o progenitor dependente de álcool. Desse modo, observamos que os dois primeiros campos aludem a vivências paranoides e desorganizadoras do psiquismo em função de um ambiente imprevisível, ameaçador e controlador. Em contrapartida, os dois últimos campos revelam o movimento dos filhos de alcoolistas no sentido da integração das experiências vividas, iniciado com o uso de estratégias defensivas para a sobrevivência emocional e que resulta na possibilidade de habitar a própria história.

No presente estudo, as reflexões sobre o sofrimento dos filhos de alcoolistas foram fundamentadas a partir da psicopatologia implícita de Winnicott (Aiello-Vaisberg, 2006; 2012; 2017), que dialoga com o existencialismo (Fulgêncio, 2015) e discorre sobre a impossibilidade de uma vida autêntica e com sentido em um ambiente interpessoal invasivo e ameaçador. Consideramos que os impactos desse sofrimento produzem ressonâncias na vida adulta, no âmbito dos relacionamentos afetivos e da realização profissional.

Tendo em vista que todos os membros da família sofrem, incluindo o próprio alcoolista que vivencia culpa, ansiedade, estigma e autoestigma (Felicissimo, 2013), enfatizamos a importância de práticas profissionais afinadas às necessidades dessa população e que considerem o papel da intergeracionalidade na produção desse tipo de sofrimento (Brittar \& Nakano, 2011; Tondowski et al., 2014).

Quanto às limitações deste estudo, podemos supor que o fato de os participantes serem membros da AL-Anon tenha permitido uma elaboração do vivido com decorrências de seu amadurecimento pessoal e da filosofia dessa instituição e, portanto, determinado os desfechos amadurecidos que observamos em seus relatos. Nesse sentido, estudos com participantes de diferentes faixas etárias e que não sejam membros da AL-Anon podem produzir resultados relevantes, ampliando a compreensão da experiência emocional desse público, usualmente negligenciado em favor de uma assistência cujo foco tem sido o alcoolista. 


\section{Referências}

Abram, J. (2000). A Linguagem de Winnicott:Dicionário das palavras e expressões utilizadas por Donald W. Winnicott. Revinter.

Aguiar, N. (2000). Patriarcado, sociedade e patrimonialismo. Sociedade e Estado, 15(2), 303-330. https://doi.org/ $10.1590 /$ S0102-69922000000200006

Aguiar, M. F. A. C., \& Menandro, P. R. M. (2012). Expectativas manifestadas por esposas de alcoolistas em tratamento no centro de atenção psicossocial álcool e drogas. Revista Brasileira em Promoção da Saúde, 25(4), 492-500. https://doi.org/ 10.5020/2557

Aiello-Fernandes, R., Ambrosio, F. F., \& Aiello-Vaisberg, T. M. J. (2012, 23 de novembro). O método psicanalítico como abordagem qualitativa: Considerações preliminares. 10a Jornada Apoiar, São Paulo, SP, Brasil. http://serefazer.psc.br/ wp-content/uploads/2013/09/aiello-fernandes-ambrosio-e-aiello-vaisberg-APOIAR-2012.pdf

Aiello-Vaisberg, T. M. J. (2004). Ser e fazer: Enquadres diferenciados na clínica winnicotiana. Ideias \& Letras.

Aiello-Vaisberg, T. M. J. (2006). A psicopatologia como teoria do sofrimento humano no pensamento de D. W. Winnicott. In I. F. Motta (Org.), Psicanálise no século XXI: As conferências brasileiras de Robert Rodman (pp. 265-284). Ideias \& Letras.

Aiello-Vaisberg, T. M. J. (2012). Paradoxo e loucura: A radicalidade do pensamento psicopatológico de D. W. Winnicott. In I. Sucar, \& H. Ramos, Winnicott Ressonâncias (pp. 231-237). Primavera.

Aiello-Vaisberg, T. M. J. (2017). Estilo clínico ser e fazer: Resposta crítico-propositiva a despersonalização e sofrimento social. Boletim - Academia Paulista de Psicologia, 37(92), 41-62.

Aiello-Vaisberg, T. M. J., Machado, M. C. L., Ayouch, T., Caron, R., \& Beaune, D. (2009). Les récits transférentiels comme présentation du vécu clinique : Une proposition méthodologique. In D. Beuane, Psychanalyse, Philosophie, Art: dialogues (pp. 39-52). L'Harmattan.

Albuquerque, F. M. P., Heimerdinger, V. S., \& Rodrigues, E. F. (2016). Implicações do uso de álcool no exercício das funções parentais na perspectiva do filho adolescente. Revista Contexto \& Saúde, 16(31), 149-164. https://doi.org/ $\underline{10.21527 / 2176-7114.2016 .31 .149-164}$

Beauvoir, S. (1967). O segundo sexo: A experiência vivida. Difusão Europeia do Livro. (Trabalho original publicado em 1949)

Beauvoir, S. (1970). O segundo sexo: Fatos e mitos. Difusão Europeia do Livro. (Trabalho original publicado em 1949)

Bleger, J. (1984). Psicologia da conduta. Artmed. (Trabalho original publicado em 1963)

Brittar, D. B., \& Nakano, A. M. S. (2011).Violência intrafamiliar: Análise da história de vida de mães agressoras e toxicodependentes no contexto da família de origem. Texto \& Contexto Enfermagem, 20(1), 17-24. https://doi.org/ $10.1590 /$ S0104-07072011000100002

Carrol, H. A., Rhew, I., \& Larimer, M. E. (2019). Moderation of relation between psychological risk factors and alcohol use by sex. Women \& Health, 60(3), 300-313. https://doi.org/10.1080/03630242.2019.1635559

Felicissimo, F. B. (2013). Habilidades sociais e estigma internalizado em alcoolistas. (Dissertação de mestrado, Universidade Federal de Juiz de Fora). Repositório Institucional UFJF. https://repositorio.uff.br/jspui/ bitstream/uff/2321/1/flavianebevilaquafelicissimo.pdf

Fulgêncio, L. (2015). Apontamentos para uma análise da influência do existencialismo moderno na obra de Winnicott. Ciência e Cultura, 67(1), 36-39. http://dx.doi.org/10.21800/2317-66602015000100013

Furtado, E. F., Laucht, M., \& Schmidt, M. (2002). Estudo longitudinal prospectivo sobre o risco de adoecimento psiquiátrico na infância e alcoolismo paterno. Revista Psiquiatria Clínica, 29(2), 71-80.

Granato, T. M. M., \& Aiello-Vaisberg, T. M. J. (2013). Narrativas interativas sobre o cuidado materno e seus sentidos afetivo-emocionais. Psicologia Clínica, 25(1), 17-35. https://doi.org/10.1590/S0103-56652013000100002

Haverfield, M. C., Theiss, J. A., \& Leustek, J. (2015). Characteristics of communication in families of alcoholics. Journal of Family Communication, 16(2), 111-127. https:// doi.org/10.1080/15267431.2016.1146284

Herrmann, F. (2001). Andaimes do real: O método da psicanálise. Casa do Psicólogo (Trabalho original publicado em 1979)

Herrmann, F. (2004). Introdução à teoria dos campos. Casa do Psicólogo. 
Psicologia: Ciência e Profissão 2021 v. 41 (n.spe 3), e218542, 1-15.

Hinrichs, J., DeFife, J., \& Westen, D. (2011). Personality subtypes in adolescent and adult children of alcoholic: A two part study. The Journal of Nervous and Mental Disease, 199(7), 487-498. https://doi.org/10.1097/ NMD.0b013e3182214268

Holla, B., Bharath, R. D., Venkatasubramanian, G., \& Benegal, V. (2019). Altered brain cortical maturation is found in adolescents with a family history of alcoholism. Addiction Biology, 24(4), 1-11. https://doi.org/10.1111/adb.12662

Lacopetti, C., Londi, I., Patussi, V., Sirigatti, S., \& Cosci, F. (2019). Life events, coping styles, and psychological well-being in children living with parents who harmfully consume alcohol. Clinical Psychology \& Psychotherapy, 26(2), 157-166. https://doi.org/10.1002/cpp.2338

Malbergier, A., \& Cardoso, L. R. D. (2011). Personalidade e dependência de drogas. In M. R. Louzã, \& T. A. Cordás (Orgs.), Transtornos da Personalidade (pp. 143-154). Artmed.

Mangueira, S. O., \& Lopes, M. V. O. (2014). Família disfuncional do contexto do alcoolismo: Análise de conceito. Revista Brasileira de Enfermagem, 67(1), 149-154. https://doi.org/10.5935/0034-7167.20140020

Omkarappa, D. B., \& Rentala, S. (2019). Ansiety, depression, self-esteem among children of alcoholic and nonalcoholic parents. Journal of Family Medicine and Primary Care, 8(2), 604- 609. https://doi.org/10.4103/jfmpc.jfmpc_282_18

Orford, J., Padin, M. F. R., Canfield, M., Sakiyama, H. M. T., Laranjeira, R., \& Mitsuhiro, S. S. (2019). The burden experienced by Brazilian family members affected by their relatives' alcohol or drug misuse. Drugs: Education, Prevention and Policy, 26(2), 157-165. https://doi.org/10.1080/09687637.2017.1393500

Pereira, V. C. L. S., Pimentel, L. F., Espínola, L. L., Azevedo, E. B., \& Filha, M. O. F. (2015). Sofrimento psíquico em adolescentes que vivenciam alteração da dinâmica familiar em consequência do alcoolismo. Revista de Enfermagem da UERJ, 23(6), 838-844. http://dx.doi.org/10.12957/ reuerj.2015.21629

Politzer, G. (1998). Crítica dos fundamentos da psicologia: A psicologia e a psicanálise (3a ed.). Editora Unimep. (Trabalho original publicado em 1928)

Santos, A. M., Silva, M. R. S., \& Silva, P. A. (2012). O cotidiano dos filhos que convivem com a mãe alcoolista. Ciência, Cuidado e Saúde, 11(4), 697-703. https:/ / doi.org/10.4025/cienccuidsaude.v1 1i4.16897

Silva, P. A., Silva, M. R. S., \& Vaz, M. R. C. (2013). Características pessoais de filhos de alcoolistas: Um estudo na perspectiva da resiliência. Avances en Enfermería, 31(2), 92-100.

Silvé Hamgstöm, A., \& Forinder, U. (2019). 'If I whistled in her ear she'd wake up': Children's narration about their experiences of growing up in alcoholic families. Journal of Family Studies, 1-23. https://doi.org/10.1080/ 13229400.2019.1699849

Stake, R. E. (2011). Pesquisa qualitativa: Estudando como as coisas funcionam. Penso.

Teixeira, E. P., Hoepers, N. J., Correa, S. M., Dagostin, V. S., \& Soratto, M. T. (2015). O enfrentamento da família diante do alcoolismo. Revista Saúde e Comunicação, 11(3), 1-14.

Tondowski, C. S., Feijó, M. R., Silva, E. A., Gebara, C. F. P., Sanchez, Z. M., \& Noto, A. R. (2014). Padrões intergeracionais de violência familiar associada ao abuso de bebidas alcoólicas: Um estudo baseado em genogramas. Psicologia: Reflexão e Crítica, 27(4), 806-814. https://doi.org/10.1590/1678-7153.201427421

Winnicott, D. W. (1975). O brincar: A atividade criativa e a busca do self. In D.W. Winnicott, O Brincar \& a Realidade (pp. 88-107). Imago. (Trabalho original publicado em 1971)

Winnicott, D. W. (1984). Consultas terapêuticas em psiquiatria infantil. Imago. (Trabalho original publicado em 1971)

Winnicott, D. W. (1990). Distorção do ego em termos de verdadeiro e falso self. In D. W. Winnicott, O Ambiente e os processos de maturação: Estudos sobre a teoria do desenvolvimento emocional (pp. 128-139). Artmed. (Trabalho original publicado em 1960)

Winnicott, D. W. (1990). Provisão para a criança na saúde e na crise. In D.W. Winnicott, O ambiente e os processos de maturação: Estudos sobre a teoria do desenvolvimento emocional (pp. 62-69). Artmed. (Trabalho original publicado em 1962)

Winnicott, D. W. (1993). A construção da confiança. In D. W. Winnicott, Conversando com os pais (pp. 139-152). Martins Fontes. (Trabalho original publicado em 1969)

Winnicott, D. W. (1993). Fatores de integração e desintegração na vida familiar. In D. W. Winnicott, A família e o desenvolvimento individual (pp. 59-72). Martins Fontes. (Trabalho original publicado em 1958)

Winnicott, D. W. (1993a). Família e maturidade emocional. In D. W. Winnicott, A família e o desenvolvimento individual (pp. 129-138). Martins Fontes. (Trabalho original publicado em 1960) 
Winnicott, D. W. (1993b). Segurança. In D. W. Winnicott, Conversando com os pais (pp. 101-107). Martins Fontes. (Trabalho original publicado em 1960)

Winnicott, D. W. (1994). O medo do colapso. In D. W. Winnicott, Explorações Psicanalíticas (pp. 70-76). Artmed. (Trabalho original publicado em 1963)

Winnicott, D. W. (2000). Preocupação materna primária. In D. W. Winnicott, Da pediatria à psicanálise: Obras escolhidas (pp. 399-405). Imago. (Trabalho original publicado em 1956)

Woodside, M. (1988). Children of alcoholics: Helping a vulnerable group. Public Health Reports, 103(6), 643-648.

\section{Antonio Richard Carias}

Psicólogo e Mestre em Psicologia como Profissão e Ciência pela Pontifícia Universidade Católica de Campinas (PUC-Campinas), Campinas - SP. Brasil.

E-mail: psicologo.antoniorichard@gmail.com

(1) https://orcid.org/0000-0001-7222-874X

\section{Tania Mara Marques Granato}

Doutora em Psicologia Clínica pelo Instituto de Psicologia da Universidade de São Paulo (USP). Tem pós-doutorado pela PUC-Campinas. Docente e orientadora do Programa de Pós-Graduação em Psicologia como Profissão e Ciência da PUC-Campinas, Campinas - SP. Brasil.

E-mail: granatotania@gmail.com

(1) https://orcid.org/0000-0002-2912-0693

Agradecimentos ao Conselho Nacional de Desenvolvimento Científico e Tecnológico (CNPq) pela bolsa de mestrado acadêmico concedida a Antonio Richard Carias e pelo financiamento desta pesquisa.

Endereço para envio de correspondência:

Rua Constância Reis Lopes, 206, Jd. Independência. CEP: 13084-490. Campinas - SP. Brasil.

Recebido 13/01/2019

Aceito 04/05/2020

Received $01 / 13 / 2019$

Approved 05/04/2020

Recibido 13/01/2019

Aceptado 04/05/2020

Como citar: Carias, A. R., \& Granato, T. M. M. (2021). O sofrimento emocional de filhos de alcoolistas: Uma compreensão psicanalítica winnicottiana. Psicologia: Ciência e Profissão, 41 (n.spe 3), 1-15. https://doi.org/ $10.1590 / 1982-3703003218542$

How to cite: Carias, A. R., \& Granato, T. M. M. (2021). The emotional distress of the children of persons with alcohol use disorder: A Winnicottian psychoanalytic perspective. Psicologia: Ciência e Profissão, 41 (n.spe 3), 1-15. https://doi.org/10.1590/1982-3703003218542

Cómo citar: Carias, A. R., \& Granato, T. M. M. (2021). El sufrimiento emocional de hijos de alcohólicos: Un entendimiento psicoanalítico winnicottiano. Psicologia: Ciência e Profissão, 41 (n.spe 3), 1-15. https://doi.org/ $10.1590 / 1982-3703003218542$ 